\title{
Carnivore occurrence: do interview-based surveys produce unreliable results?
}

\author{
N. Caruso, E. Luengos Vidal, M. Guerisoli and M. Lucherini
}

\begin{abstract}
Interviews with local people have been widely used by biologists as a cost-effective approach to studying certain topics in wildlife ecology and conservation. However, doubts still exist about the validity and quality of the information gathered, especially in studies targeting cryptic or elusive species, such as carnivores. We assessed the reliability of interviews $(n=155)$ in detecting the presence of three species of carnivores with different characteristics, by comparing interview results with data obtained through camera trapping surveys at 52 sites in central Argentina. The degree of concordance between methods was low for Geoffroy's cat Leopardus geoffroyi and especially for the puma Puma concolor. However, Geoffroy's cats were detected more frequently by camera traps than interviews, whereas the opposite was true for pumas. For the pampas fox Pseudalopex gymnocercus, a less elusive species, we observed a high degree of concordance and a similar probability of occurrence between methods. Our results indicate that data obtained by interviewing local inhabitants should be used with caution because the information about species presence provided by local people may be inaccurate and biased.
\end{abstract}

Keywords Argentina, camera trapping, Geoffroy's cat, pampas fox, puma, questionnaires

To view supplementary material for this article, please visit http://dx.doi.org/10.1017/So030605315001192

\section{Introduction}

The use of interviews in ecological studies is increasing because they are a particularly cost-effective approach to certain topics, such as stakeholder perceptions in wildlife management, human impacts on wild species, and interdisciplinary studies (White et al., 2005). Properly designed interviews have the potential to provide a credible,

N. Caruso* (Corresponding author), E. Luengos Vidal $\dagger$, M. Guerisoli ${ }^{*}$ and M. LuCherini ${ }^{\star}$ Grupo de Ecología Comportamental de Mamíferos, Cát. Fisiología Animal, Depto. Biología, Bioquímica y Farmacia, Universidad Nacional del Sur, San Juan 670, 8000 Bahía Blanca, Argentina

E-mail nccaruso@gmail.com

*Also at: CONICET (Consejo Nacional de Investigaciones Científicas y Técnicas), Buenos Aires, Argentina

$\dagger$ Also at: INBIOSUR-CONICET (Instituto de Investigaciones Biológicas y Biomédicas del Sur), Bahía Blanca, Argentina

Received 5 May 2015. Revision requested 24 June 2015.

Accepted 28 September 2015. First published online 25 April 2016. cost-effective alternative to large-scale field surveys for direct records or signs of target species, especially for species that are rare and difficult to detect (Larivière et al., 2000; van der Hoeven et al., 2004; Pillay et al., 2011; Zeller et al., 2011). Although interviews are widely used in ecological studies, there are doubts within the conservation and research communities about the validity and quality of information they provide (White et al., 2005; Soto-Shoender \& Main, 2013). This is especially true in situations where interviewees may provide biased information; for example, Msoffe et al. (2007) noted that local people have better knowledge of species that tend to cause more problems than of more rare and shy species.

The use of camera traps for wildlife research dates back to the early 2oth century (Chapman, 1927) but has become more affordable since the 1990s. Despite its still relatively high cost (Silveira et al., 2003), camera trapping is now a mainstream tool for mammal inventories, particularly in studies involving species that are difficult to observe because of their rarity or secretive behaviour (Cutler \& Swann, 1999; Rowcliffe \& Carbone, 2008). Mammalian carnivores tend to have large home ranges, low population densities and slow population growth rates (Gittleman, 2001). The combination of these traits with elusiveness results in small sample sizes and low detection probabilities (Burton et al., 2012). Both camera trapping and interviews have frequently been used to overcome these limitations. Because of their lower initial and running costs and time requirements, interviewbased surveys are an attractive alternative to remote photography, especially when projects need to cover extensive areas (Zeller et al., 2011; Kotschwar Logan et al., 2015). Local information may, however, yield unreliable results and should be checked with other field research (Can \& Togan, 2009).

Our main objective was to assess the reliability of interviews in detecting the presence of three species of carnivores with different characteristics by explicitly testing interview results against data obtained through camera trapping surveys. The three species selected (Geoffroy's cat Leopardus geoffroyi, puma Puma concolor and pampas fox Pseudalopex gymnocercus) differ in their relative detectability and degree of conflict with human activities (Supplementary Table S1). We hypothesized that the reliability of interviews with rural inhabitants for detecting the occurrence of wildlife (1) varies as a function of species detectability (thus, we predicted that the level of coincidence between data obtained through both techniques would be higher for those species with highest detectability), (2) varies as a function of the degree of human-wildlife conflict, and 
(3) depends on the level of familiarity the interviewees have with the species surveyed (thus, we predicted that the similarity between the data obtained from interview-based surveys and camera trapping would be greatest in the case of people who had lived in the study area for the longest time).

\section{Study area}

We carried out both camera trapping surveys and interviews in Villarino and Patagones counties (which cover a total of $27,300 \mathrm{~km}^{2}$ ) in the southernmost part of Buenos Aires province in central Argentina (Fig. 1). The study area belongs to the Argentine Espinal ecoregion, characterized by a temperate, semiarid climate (Fernández \& Busso, 1999). The topography is mostly flat and the natural vegetation is characterized by xerophytic deciduous woodlands, prairies dominated by grasslands, and prairies intermixed with extensive scrublands. This region is inhabited by a unique vertebrate community that is threatened by agricultural expansion and the consequent modification of natural habitats and increased conflict between people and wildlife.

\section{Methods}

During 2010-2013 we conducted semi-structured interviews with local people to gather presence data on carnivores (Supplementary Material 1). Location points were selected at random on a map of the study area and interviews were carried out in properties located at these points; however, to avoid spatial autocorrelation we selected interview sites that were at least $4 \mathrm{~km}$ apart. The protocol specifically targeted people most knowledgeable about wildlife in the area (i.e. farmers and ranchers who worked on the selected properties). Interviews were conducted informally by two or three researchers in each case. Because hunting of the target species is illegal, we stated clearly at the beginning of each interview that we were from a non-governmental organization and that all information provided would be treated anonymously. A range of data about the presence of certain species, their habitat use and attitudes towards them were recorded. However, for the scope of this study we used only the information obtained on the presence/absence of carnivores. We asked the interviewees to list and describe the carnivores known to occur on their property (the mean property size of the interviewees was $6.84 \mathrm{~km}^{2}$ ) during the previous 2 years. Subsequently, we showed reference cards with photographs of various species and asked each respondent to confirm which he or she had seen. If this revealed any uncertainty concerning the validity of the response, the interview was discarded. This is a commonly used procedure in interview-based surveys and it facilitated the identification of the most reliable interviewees (GarciaAlaniz et al., 2010; Schulz et al., 2014). Interviews followed

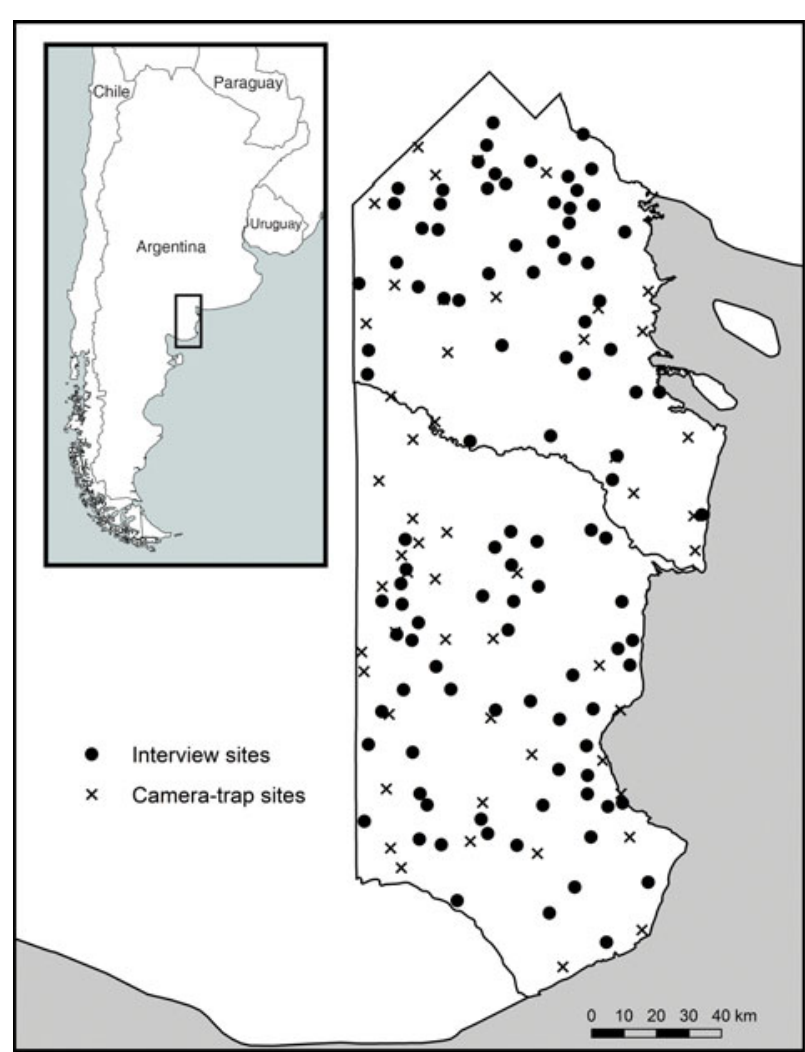

FIg. 1 Location of interview and camera trapping sites in Villarino and Patagones counties in central Argentina.

the ethical guidelines of the Social Research Association (SRA, 2003).

Systematic camera-trap surveys were conducted during January-May in 2011-2013. To randomize the spatial arrangement of the sampling stations and thus to survey a representative sample we used a geographical information system (GIS) layer of the study area to create 100 random points at least $6 \mathrm{~km}$ apart. We deployed cameras at only 52 of these points because of logistical restrictions and to adjust the survey design to the number of cameras available. To maximize detection probability five cameras were arranged in a square at each site, with one camera at each vertex (c. $1.5 \mathrm{~km}$ apart) and one in the centre. Camera traps operated for 35 days, $24 \mathrm{~h}$ per day. Sampling effort was calculated as the product of the total number of stations and the number of effective days of sampling (excluding those days when cameras did not work), which totalled 7,054 camera trap days.

For each camera-trap site we compared the presence/ absence data collected with those obtained in the closest interview (Supplementary Table S2). We calculated the probability of occurrence for both methods, to estimate their respective capacity to detect the presence of each of the three target carnivore species. For the camera trapping we applied a single-species/single-season occupancy approach (MacKenzie, 2006). This method facilitates simultaneous estimation of site occupancy $(\Psi)$ and detection 
probability $(p)$ for the focal species. There are three possible outcomes to this approach: (1) the site is occupied and the species is detected $(\Psi . p),(2)$ the species is present but not detected $(\Psi .(1-p)$, or $(3)$ the species is not present and therefore is not detected $(1-\Psi)$. The detection probabilities can be estimated by sampling each site on multiple occasions. $\Psi$ (and its $95 \%$ confidence intervals) is obtained as a projected parameter in a maximum-likelihood estimation; it indicates the proportion of sites occupied during the sample period weighted by the detection probability of the species. To reproduce what typically happens in interviewbased surveys, in which no replicates are available, we computed only a naïve probability of occurrence.

To measure the degree of concordance (i.e. spatial association) between the two methods we computed the $r_{\mathrm{n}}$ index (Zar, 1999). This index measures the level of correlation among nominal variables, from -1 (total discordance) to 1 (total concordance).

To test whether our assessment of the reliability of interviews was affected by the spatial proximity between the locations sampled with the two methods, we created four categories of distance $(\leq 25 \mathrm{~km}, \mathrm{n}=52 ; \leq 15 \mathrm{~km}, \mathrm{n}=45$; $\leq 10 \mathrm{~km}, \mathrm{n}=35 ; \leq 5 \mathrm{~km}, \mathrm{n}=19)$ and recalculated the $r_{\mathrm{n}}$ index for each of them.

As the reliability of informants can be affected by their degree of familiarity with the study area (Turvey et al., 2014), we divided our sample of interviewees into two groups: residents, who lived permanently or most of the time on the ranch where we interviewed them, and nonresidents, who spent most of their time elsewhere (Conforti \& de Azevedo, 2003; Soto-Shoender \& Main, 2013). We then compared the probability of occurrence and $r_{n}$ index between the two groups for each species.

In all cases we tested the statistical significance of the variations in the $r_{n}$ index and the probability of occurrence, assessing the overlap in confidence intervals estimated through a bootstrap procedure (Efron \& Tibshirani, 1986). All statistical analyses were performed using $R$ v. 3.o.1 (R Development Core Team, 2013).

\section{Results}

We completed 155 interviews. The duration of the interviewees' residency in the study area varied; some had lived there for only 1 month, others their entire lives. The male : female ratio was $5: 1$ and the median age of the interviewees was 48 years (range $16-82) ; 48.4 \%$ of interviewees $(n=75)$ were residents, and $51.6 \%(\mathrm{n}=80)$ were non-residents. We obtained a total of 823 photographic records of the three carnivore species (204 of Geoffroy's cat, 57 of the puma, and 562 of the pampas fox).

The degree of concordance between interviews and camera trapping was close to o for Geoffroy's cat $\left(r_{\mathrm{n}}=0.07\right)$, and
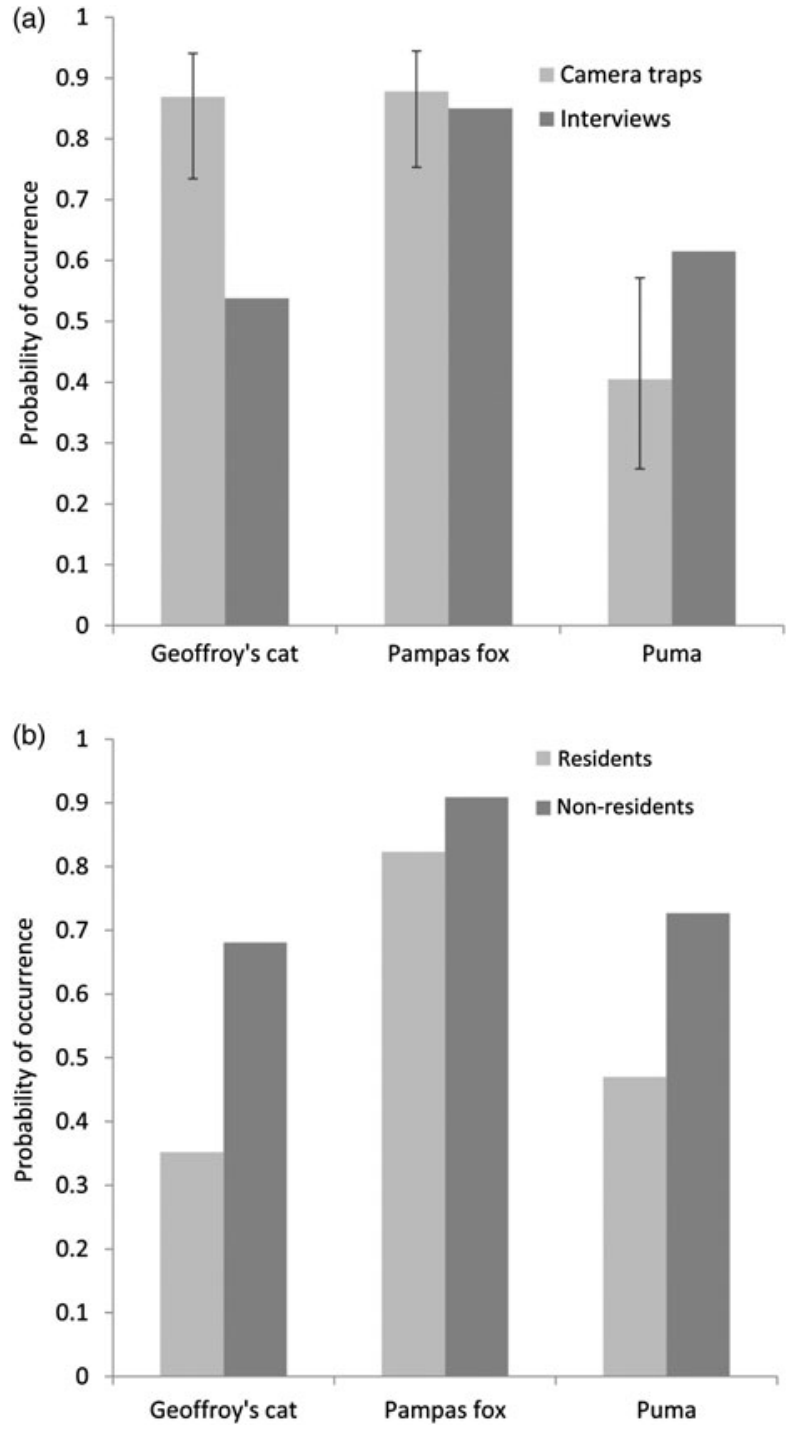

FIG. 2 Probabilities of occurrence of Geoffroy's cat Leopardus geoffroyi, the pampas fox Pseudalopex gymnocercus and the puma Puma concolor in central Argentina, based on (a) camera trapping (bars show the 95\% confidence intervals obtained through detection probabilities) and interviews with local inhabitants, and (b) the responses of residents and non-residents.

this felid was detected more frequently by camera traps than it was reported in interviews (Fig. 2a). The greatest discordance between methods was for the puma $\left(r_{\mathrm{n}}=-0.15\right)$, which was reported more frequently by interviews than it was detected by camera traps (Fig. 2a). The interview results suggested that the puma was more common than Geoffroy's cat (their probabilities of occurrence were 0.62 and 0.54 , respectively). For the pampas fox there was a high degree of concordance between methods $\left(r_{\mathrm{n}}=0.65\right)$ and a similarly high probability of detection by camera traps and reporting in interviews (probability of occurrence according to interviews $=0.85$; Fig. $2 \mathrm{a}$ ). There were substantial overlaps in the $95 \% \mathrm{CI}$ of $r_{\mathrm{n}}$ for all three species, indicating that 
distance between interview and camera-trap sites did not have a significant effect on the degree of concordance between methods (Fig. 3).

There was no marked difference in the probability of occurrence of the pampas fox reported by residents and nonresidents (Fig. 2b). Residents reported both the puma and Geoffroy's cat were rarer, compared with non-residents (Fig. 2b). However, because the camera traps indicated that the probability of occurrence of the puma was lower than that of Geoffroy's cat (Fig. 2a), in the case of Geoffroy's cat the concordance between methods was greater for non-residents than residents (Fig. 2b), contrary to our expectations. In spite of these variations across species, in all cases the degree of concordance between methods did not differ significantly when residents were compared to nonresidents (Fig. 4).

\section{Discussion}

Although the suitability of interviews as a replacement for field surveys has been discussed previously (e.g. Msoffe et al., 2007; Can \& Togan, 2009), to our knowledge this is the first attempt to explicitly test the reliability of interview data for surveying mammals against a robust method of data collection. We found that reports obtained by interviewing local inhabitants were unreliable and yielded inaccurate and biased presence data for two of the three species we surveyed. This conclusion was supported by the discrepancy between interviews and the probabilities of occurrence estimated by camera trapping, and by the poor spatial association between methodologies. Our results support the hypothesis that the reliability of results collected from interviews varies between species. Although it is not easy to understand which factors may affect this bias, interviewees appeared to underestimate the occurrence of Geoffroy's cat, a small cat that is cryptic and inconspicuous. On the contrary, interviews indicated an overestimation of the presence of the puma, a similarly elusive but charismatic species that often comes into conflict with people (Supplementary Table S1). For the pampas fox, a less elusive species, we found a high degree of concordance and a similar probability of occurrence between methods.

Contrary to our expectation, neither the degree of familiarity of the interviewees with the study area (a proxy for their familiarity with the selected species) nor the distance between the sites of interviews and camera traps had a significant effect on the consistency of the answers regarding the presence of carnivores. This suggests that the lack of concordance of interviews with camera trap data was not affected by our sampling protocols.

Interviews with local people have been used in combination with site occupancy modelling to complete rapid, large-scale surveys of jaguars Panthera onca and their

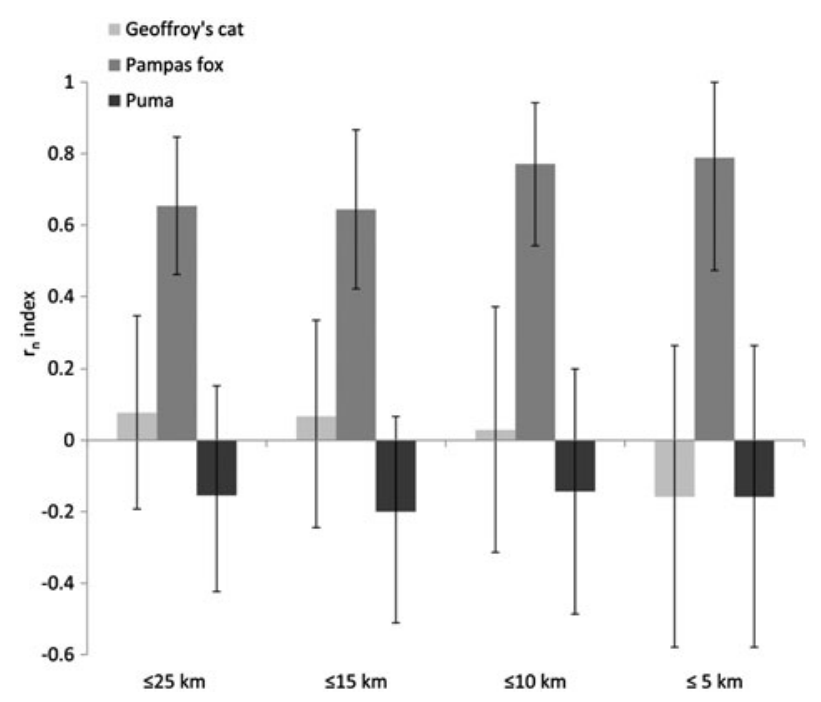

FIG. 3 Variation in the degree of concordance $\left(r_{\mathrm{n}}\right.$ index and 95\% confidence intervals) between interviews and camera trapping with decreasing distances between sites, in surveys of Geoffroy's cat, the pampas fox and the puma in central Argentina (Fig. 1). The values of $r_{\mathrm{n}}$ vary from -1 (total discordance) to 1 (complete concordance).

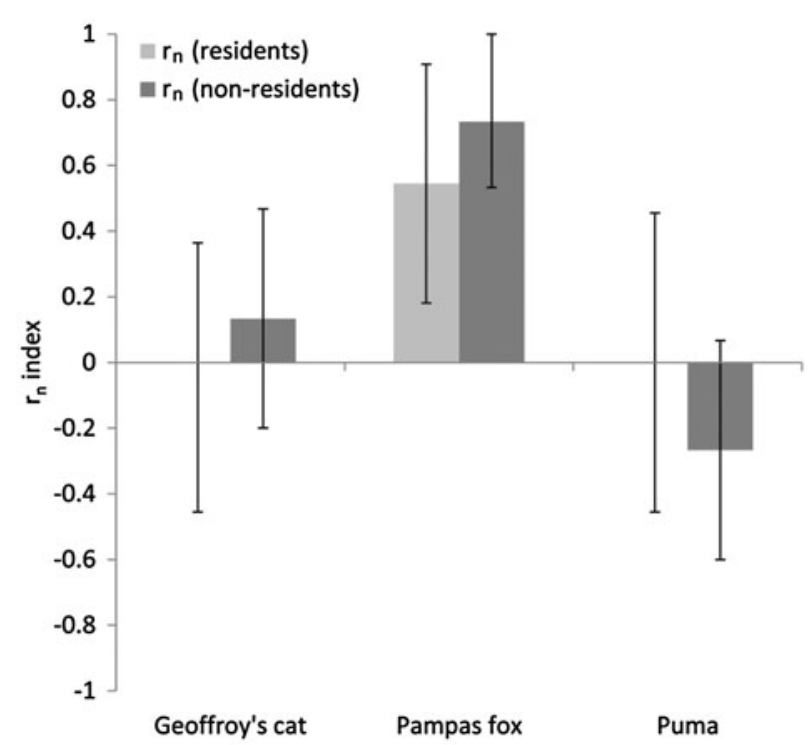

FIG. 4 Variations in the responses of residents and non-residents in terms of the degree of concordance between survey methods ( $r_{\mathrm{n}}$ index, with $95 \%$ confidence intervals) for Geoffroy's cat, the pampas fox and the puma in central Argentina.

prey, and identify environmental covariates affecting presence (Zeller et al., 2011; Petracca et al., 2014). Although the sampling design of these studies compensated for imperfect detection (Zeller et al., 2011; Petracca et al., 2014), our results suggest that the occurrence of conflictual and charismatic species, such as the puma in our study, may 
be overestimated by interviewees, leading to management decisions that depart from a precautionary approach to wildlife conservation.

Ideally, a definitive test of the reliability of interview data for reporting the presence of species requires that the true presence of the study species should be known. Some caution is required because we are assuming that our cameratrapping results reflect the true occurrence of the three species of carnivore we surveyed. This technique has proven to be effective for surveying cryptic species, such as carnivores, over large areas (Moruzzi et al., 2002) and to provide reliable results on their occurrence when species-specific variations in detection probabilities are accounted for (MacKenzie et al., 2002). Thus, despite the fact that interviews have advantages over more time-consuming and expensive methods for collecting data on wildlife presence, and have frequently been used to study the distribution of mammals (Chiarello, 1999; Larivière et al., 2000; Pillay et al., 2011), we conclude that they should be used with caution when surveying carnivores, especially when the species targeted are of conservation concern and biased results may lead to inappropriate conservation measures. Typically, interviews are not intended to replace other methodologies but to complement them. In agreement with previous suggestions (Anadón et al., 2009), our data indicate that in every case where interviews are used the data gathered should be compared and calibrated with data from other methodologies.

\section{Acknowledgements}

We thank S. Remillard, M. Saunier, M. Ricard, A. Ferland and C. Gagnon for field support and interesting discussions, and the ranch owners and the staff of Instituto Nacional de Tecnología Agropecuaria, particularly C. Winchel, A. Pezola, F. Castoldi, D. Iurman, A. Garat and D. Koellner, who facilitated our work. B. Tallon edited the manuscript for English, and two anonymous reviewers provided useful comments. We are especially grateful to E. Casanave for her critical support throughout the project. NC, MG and ELV were supported by scholarships from Consejo Nacional de Investigaciones Científicas y Técnicas (CONICET). This work was funded by Proyectos de Investigación Plurianuales (CONICET), Secretaría de Ciencia y Técnica-Universidad Nacional del Sur $(24 \mathrm{~B} 198)$, the Wild Felid Research and Management Association, and the Felidae Conservation Fund.

\section{References}

Anadón, J.D., Giménez, A., Ballestar, R. \& Pérez, I. (2009) Evaluation of local ecological knowledge as a method for collecting extensive data on animal abundance. Conservation Biology, 23, 617-625.
Burton, A.C., SAm, M.K., BalangtaA, C. \& Brashares, J.S. (2012) Hierarchical multi-species modeling of carnivore responses to hunting, habitat and prey in a West African protected area. PLoS ONE, 7(5), e38007.

CAN, Ö.E. \& TogAN, İ. (2009) Camera trapping of large mammals in Yenice Forest, Turkey: local information versus camera traps. Oryx, 43, 427-430.

Cha PMAn, F.M. (1927) Who treads our trails. The National Geographic Magazine, 52, 330-345.

Chiarello, A.G. (1999) Effects of fragmentation of the Atlantic forest on mammal communities in south-eastern Brazil. Biological Conservation, 89, 71-82.

Conforti, V.A. \& de Azevedo, F.C.C. (2003) Local perceptions of jaguars (Panthera onca) and pumas (Puma concolor) in the Iguaçu National Park area, south Brazil. Biological Conservation, 111, 215-221.

Cutler, T.L. \& Swann, D.E. (1999) Using remote photography in wildlife ecology: a review. Wildlife Society Bulletin, 27, 571-581.

Efron, B. \& Tibshirani, R. (1986) Bootstrap methods for standard errors, confidence intervals, and other measures of statistical accuracy. Statistical Science, 1, 54-75.

Fernández, O.A. \& Busso, C.A. (1999) Arid and Semi-Arid Rangelands: Two Thirds of Argentina. Agricultural Research Institute, Borgarnes, Iceland.

Garcia-Alaniz, N., Naranjo, E.J. \& Mallory, F.F. (2010) Humanfelid interactions in three mestizo communities of the Selva Lacandona, Chiapas, Mexico: benefits, conflicts and traditional uses of species. Human Ecology, 38, 451-457.

Gittleman, J.L. (2001) Carnivore Conservation. Cambridge University Press, Cambridge, UK.

Kotschwar Logan, M., Gerber, B.D., Karpanty, S.M., Justin, S. \& RABENAHY, F.N. (2015) Assessing carnivore distribution from local knowledge across a human-dominated landscape in centralsoutheastern Madagascar. Animal Conservation, 18, 82-91.

Larivière, S., Jolicoeur, H. \& Crête, M. (2000) Status and conservation of the gray wolf (Canis lupus) in wildlife reserves of Québec. Biological Conservation, 94, 143-151.

MacKenzie, D.I. (2006) Occupancy Estimation and Modeling: Inferring Patterns and Dynamics of Species Occurrence. Elsevier, San Diego, USA.

MacKenzie, D.I., Nichols, J.D., Lachman, G.B., Droege, S., Royle, J.A. \& LANGTimm, C.A. (2002) Estimating site occupancy rates when detection probabilities are less than one. Ecology, 83, 2248-2255.

Moruzzi, T.L., Fuller, T.K., DeGraaf, R.M., Brooks, R.T. \& Li, W. (2002) Assessing remotely triggered cameras for surveying carnivore distribution. Wildlife Society Bulletin, 30, 380-386.

Msoffe, F., Mturi, F.A., Galanti, V., Tosi, W., Wauters, L.A. \& Tosi, G. (2007) Comparing data of different survey methods for sustainable wildlife management in hunting areas: the case of Tarangire-Manyara ecosystem, northern Tanzania. European Journal of Wildlife Research, 53, 112-124.

Petracca, L.S., Ramírez-Bravo, O.E. \& Hernández-Santín, L. (2014) Occupancy estimation of jaguar Panthera onca to assess the value of east-central Mexico as a jaguar corridor. Oryx, 48, 133-140.

Pillay, R., Johnsingh, A.J.T., Raghunath, R. \& Madhusudan, M.D. (2011) Patterns of spatiotemporal change in large mammal distribution and abundance in the southern Western Ghats, India. Biological Conservation, 144, 1567-1576.

R Development Core Team (2013) R: A Language and Environment for Statistical Computing. R Foundation for Statistical Computing, Vienna, Austria. 
Rowcliffe, J.M. \& Carbone, C. (2008) Surveys using camera traps: are we looking to a brighter future? Animal Conservation, 11, 185-186.

Schulz, F., Printes, R.C. \& Oliveira, L.R. (2014) Depredation of domestic herds by pumas based on farmers' information in Southern Brazil. Journal of Ethnobiology and Ethnomedicine, 10, 73.

Silveira, L., JА́сомо, A.T.A. \& Diniz-Filho, J.A.F. (2003) Camera trap, line transect census and track surveys: a comparative evaluation. Biological Conservation, 114, 351-355.

Soto-Shoender, J.R. \& Main, M.B. (2013) Differences in stakeholder perceptions of the jaguar Panthera onca and puma Puma concolor in the tropical lowlands of Guatemala. Oryx, 47, 109-112.

SRA (Social Research Association) (2003) Ethical Guidelines. Http://the-sra.org.uk/wp-content/uploads/ethicso3.pdf [accessed 9 March 2016].

Turvey, S.T., Fernández-Secades, C., Nuñez-Miño, J.M., Hart, T., Martinez, P., Brocca, J.L. \& Young, R.P. (2014) Is local ecological knowledge a useful conservation tool for small mammals in a Caribbean multicultural landscape? Biological Conservation, $169,189-197$.

van der Hoeven, C.A., de Boer, W.F. \& Prins, H.H.T. (2004) Pooling local expert opinions for estimating mammal densities in tropical rainforests. Journal for Nature Conservation, 12, 193-204.

White, P.C.L., Vaughan Jennings, N., Renwick, A.R. \& Barker, N.H.L. (2005) Questionnaires in ecology: a review of past use and recommendations for best practice. Journal of Applied Ecology, 42, 421-430.

ZAR, J.H. (1999) Biostatistical Analysis. Prentice Hall, Upper Saddle River, USA.

Zeller, K.A., Nijhawan, S., Salom-Pérez, R., Potosme, S.H. \& Hines, J.E. (2011) Integrating occupancy modeling and interview data for corridor identification: a case study for jaguars in Nicaragua. Biological Conservation, 144, 892-901.

\section{Biographical sketches}

Nicolas CARUSo's research interests include conservation biology and ecological modelling, and he has been working on carnivores since 2005 . He is currently focusing on land-use changes and their effects on the carnivore community. Estela Luengos Vidal has worked on a number of research and conservation projects on mammals in Argentina, and her research focuses on human-carnivore interactions. Maria Guerisoli is studying puma ecology in Argentina; she has previously worked on large carnivores in Italy. MAURo LUCHERINI specializes in the conservation biology of carnivores and the behavioural ecology of wild mammals. Since 1998 he has been leading research and conservation projects in the central lowlands and north-western highlands of Argentina. 